\title{
Laboreal
}

Volume 15 N$^{\circ} 2$ | 2019

Varia

\section{3 de dezembro : Dia Mundial da Não Utilização de Pesticidas}

3 de diciembre: Día Mundial del No uso de Plaguicidas

3 décembre: Journée mondiale sans utilisation de pesticides

December $3^{\text {rd: }}$ World Day of No Pesticide Use

\section{Alexis Uriel Blanklejder}

\section{(2) OpenEdition}

Journals

Edição electrónica

URL: http://journals.openedition.org/laboreal/15335

DOI: 10.4000/laboreal.15335

ISSN: 1646-5237

\section{Editora}

Universidade do Porto

Refêrencia eletrónica

Alexis Uriel Blanklejder , « 3 de dezembro : Dia Mundial da Não Utilização de Pesticidas », Laboreal [Online], Volume $15 \mathrm{~N}^{0} 2$ | 2019, posto online no dia 01 dezembro 2019, consultado o 15 setembro 2020. URL : http://journals.openedition.org/laboreal/15335

Este documento foi criado de forma automática no dia 15 setembro 2020.

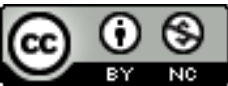

Laboreal está licenciado com uma Licença Creative Commons - Atribuição-NãoComercial 4.0 Internacional. 


\title{
3 de dezembro : Dia Mundial da Não Utilização de Pesticidas
}

\author{
3 de diciembre: Día Mundial del No uso de Plaguicidas \\ 3 décembre: Journée mondiale sans utilisation de pesticides \\ December $3^{\text {rd: }}$ : World Day of No Pesticide Use
}

Alexis Uriel Blanklejder

1 Ocorreram mais de 2000 mortes numa questão de horas, às que se seguiram outros milhares nas semanas seguintes, multiplicadas por centenas se nos remetermos aos que viram a sua saúde gravemente afetada de modo permanente, chegando assim a contabilizar mais de 200.000. Partindo destes números, bastante vagos pela falta de exatidão perante semelhante tragédia, poderíamos pensar que se tratou de uma guerra que mudou a história de dois países. Mas tratou-se de um acidente, um acidente de enormes proporções, inclusivamente maior, no que se refere ao número de vítimas, do que o famoso Titanic, cujo naufrágio causou cerca de 1513 mortes.

2 A efeméride está associada ao tipo de substância que originou a catástrofe, um pesticida. Como alguns devem ter deduzido, estou a referir-me ao acidente ocorrido em Bhopal, em 1984. Se bem que a palavra efeméride, que provém do grego ephemeros, se refere ao que "dura só um dia" (Soca, 2010), não reflete o que a fuga do tóxico provocou. Foi preciso muito menos de um dia para causar tantas vítimas. O Dia Mundial da Não Utilização de Pesticidas celebra-se a 3 de dezembro. Um evento pouco divulgado, bem como o acidente de Bhopal, com a exceção dos meios que se interessam por temas ecológicos ou de segurança industrial. Para além de se tratar de um acidente causado pela fuga de um produto químico, também se trata do pior acidente industrial da história no que se refere ao número de vítimas.

\section{Como tudo aconteceu...}

3 Na cidade de Bhopal, capital de Madhya Pradesh, na Índia, estava em funcionamento, de modo parcial, uma fábrica de pesticidas que, na sua maioria, pertencia à Union 
Carbide Corporation, sendo que a parte restante era propriedade, ora do governo da Índia, ora de um grande número de acionistas. Esta fábrica embalava produtos químicos intermédios para mais tarde os misturar e obter um pesticida denominado Sevin. Entre os produtos químicos que constituíam o Sevin, um pesticida ligeiramente tóxico, encontravam-se o alfa-naftol e o isocianato de metilo (MIC), os quais deviam ser misturados, diluídos com um pó não toxico e embalados na fábrica (Trotter, Day, \& Love, 1989).

4 As falhas operativas que conduziram à tragédia tiveram início na noite de 2 de dezembro, tendo eclodido na madrugada de 3 de dezembro de 1984, quando ocorreu um aumento da pressão no tanque número 610 de armazenamento de isocianato de metilo (MIC) (Fischer, 1996). A sobrepressão teve origem numa reação exotérmica do MIC ao entrar em contacto com água, cloreto de sódio e restos metálicos. 0 gás sob pressão dentro do tanque começou a escapar para a atmosfera através das válvulas de segurança, que rebentaram devido aos níveis de pressão alcançados pela mistura, aumentando a fuga da mistura. Por sua vez, as condições de temperatura do gás causaram a sua decomposição em várias substâncias altamente tóxicas, e inclusivamente letais, como o fosgénio, a monometilamina e o cianídrico, todas estas com uma densidade superior ao ar, o que gerou uma nuvem tóxica que se abateu nas imediações cobrindo uma superfície de mais de 60 quilómetros quadrados. Nas proximidades da fábrica, em lugar de existir um espaço desabitado e livre de construções, encontrava-se uma densa acumulação de casas de pessoas com baixos recursos, que cresceu como qualquer outro bairro de lata, onde quer que seja. De madrugada, estas casas começaram a ser invadidas pelo nevoeiro letal. As vítimas da pobreza de sempre, tornavam-se agora vítimas de uma catástrofe industrial.

\section{As causas}

5 Ao analisar o acidente de Bhopal, Reason (2009) enumera uma longa série de fatores. 0 denominado modelo do Queijo Suíço toma em consideração a complexidade dos eventos que conduziram a este terrível final. Entre estes, julgo ser útil distinguir os que originaram a fuga do tanque 610 e que ocasionaram um tão elevado número de vítimas.

\section{A fuga do tanque 610}

6 Entre as denominadas falhas latentes, Reason enumera, como erros do sistema, a falta de adequação da fábrica em termos de segurança para o armazenamento do metil isocianato (MIC), uma vez que estava guardada uma quantidade de MIC muito superior à necessária para sua utilização. Uma longa série de deficiências de segurança por resolver, detetadas em inspeções anteriores e após seis acidentes prévios, entre os quais se contava pelo menos um relativo a uma fuga de gases.

7 Quando se analisaram os erros de gestão, identificou-se uma redução da quantidade de pessoal das operações e de manutenção, falta de pessoal qualificado presente na fábrica e a desativação da sirene imediatamente após esta ter disparado.

8 Ao nível da instalação, os erros detetados foram o não funcionamento do sistema de refrigeração e a ausência de sensores automáticos de temperatura. No painel de controlo, faltavam indicadores de pressão e de temperatura, não havia monitores em 
linha dos tanques MIC, as válvulas da sala de controlo não possuíam indicadores de posição e o monitor de pressão indicava uma leitura de 30 psi abaixo do valor real. A capacidade da instalação era insuficiente para a depuração de gases, a chaminé de combustão dos gases em excesso estava desligada e o tratamento dos gases de ventilação encontrava-se em modo inativo. As tubagens utilizadas para o transporte do MIC eram de ferro, material que fez parte da reação que originou o acidente. Além disso, o número de máscaras de gás do equipamento de proteção pessoal não era suficiente.

\section{Sobre a dimensão da tragédia}

9 A fábrica estava rodeada por uma área densamente povoada e o grande número de vítimas, não o acidente que as originou, está vinculado a esta condição. Se as circunstâncias não fossem estas, provavelmente as vítimas mortais teriam sido apenas os próprios operários da fábrica que não tivessem meios para se proteger dos gases tóxicos. É essencial mencionar que esta fábrica não produzia inicialmente Sevin, mas armazenava-o como produto acabado para distribuição (Trotter, Day, \& Love, 1989). Foi a sua elevada procura que conduziu à modificação da fábrica para produzir o pesticida $\mathrm{e}$, consequentemente, o que alterou substancialmente o risco para a população circundante. Adicionalmente, tal como se explicou mais acima, as áreas vizinhas da fábrica foram sendo paulatinamente ocupadas dando lugar a um bairro de lata, uma condição que não foi sujeita a qualquer controlo.

\section{Os outros efeitos de Bhopal}

10 Tal como o caso de outros acidentes com uma magnitude semelhante, e inclusivamente muito menores, o de Bhopal tornou-se no motor, ou como referem alguns autores (Khan, 2007), num catalisador de melhorias dos processos de segurança e das alterações na legislação específica, tendo mesmo dado origem a uma nova categoria para classificar este tipo de desastres (Kliesch, 1990). Surgiu assim a denominação de Acidente Grave, definido pela Convenção n.. 174 da Organização Internacional do Trabalho (Convenção-C174, 1993, p. 2) como :

\footnotetext{
“(..) um acidente grave designa qualquer acontecimento repentino, como uma emissão, um incêndio ou uma explosão de grande magnitude, no decurso de uma atividade dentro de uma instalação exposta a riscos de acidentes graves, no qual estejam envolvidas uma ou várias substâncias perigosas e que exponha os trabalhadores, a população ou o ambiente a um perigo grave, imediato ou diferido".
}

11 Nesta mesma categoria, podemos encontrar os acidentes de : Beek (1975), Seveso (1976), Basileia (1986), Flixborough (1974), México D.F. (1984), Deepwater Horizon (2010).

\section{Conclusão}

12 Ao passo que a efeméride do dia 3 de dezembro permanece na memória só de alguns, associada sobretudo aos produtos químicos, o pior acidente industrial da história continua a deixar uma marca mórbida no corpo de crianças indianas que nascem com 
malformações, atrasos ou surdez, como consequência dos efeitos genéticos da tragédia. O Dia da Não Utilização de Pesticidas poderia igualmente ser o Dia para a Prevenção dos Acidentes Graves. Com o propósito de cobrir necessidades, há uma longa série de atividades desenvolvidas pelo Homem que podem conduzir a eventos semelhantes. Possivelmente, o facto de pensar nestes permite a sua redução, ainda que só em parte.

\section{BIBLIOGRAFIA}

Fischer, M. (1996). Union carbide's Bhopal incident : a retrospective. Journal of Risk and Uncertainty, 12(2-3), 257-269. https://doi.org/10.1007/BF00055797

Kahn, M. (2007). Environmental disasters as risk regulation catalysts? The role of Bhopal, Chernobyl, Exxon Valdez, Love Canal, and Three Mile Island in shaping U.S. environmental law. Journal or Risk and Uncertainty, 35(1), 17-43. https://doi.org/10.1007/s11166-007-9016-7

Kliesch, G. (1990). Control de riesgos de accidentes mayores. Manual práctico. Ginebra : OIT.

Organização Internacional do Trabalho (1993). Convenio sobre la preventión de accidents industriales mayores (número 174). https://www.ilo.org/dyn/normlex/es/f ?p =NORMLEXPUB :12100 :

0 : :NO : :P12100_ILO_CODE :C174

Reason, J. (2009). El Error humano. Madrid : Modus Laborandi.

Soca, R. (2010). La fascinante historia de las palabras. Bogotá: Rey Naranjo Editores.

Trotter, R., Day, S., \& Love, A. (1989). Bhopal, India and union carbide: the second tragedy. Journal of Business Ethics, 8(6), 439-454. https://doi.org/10.1007/BF00381810

\section{AUTOR}

\section{ALEXIS URIEL BLANKLEJDER}

Faculdade de Ciências Sociais (FSC), Universidade de Buenos Aires (UBA), Chile 1860, 2º piso "7" (C1227AAB), Cidade Autónoma de Buenos Aires. Argentina.

alexisub@gmail.com 